\title{
Study on the Evaluation of Red Culture Tourism Resources in Qingyang
}

\author{
Jinghua Zhang ${ }^{1}$, Fei Wang ${ }^{2}$ \\ ${ }^{1}$ College of Economics and Management, Longdong University, Qingyang, Gansu, 745000, P.R. China \\ ${ }^{2}$ College of History and Geography, Longdong University, Qingyang, Gansu, 745000, P.R. China
}

Keywords: Qingyang, Red Culture, Tourism Resources, Development and Utilization

\begin{abstract}
The paper uses AHP (Analytic Hierarchy Process analytic hierarchy process (AHP) to construct the evaluation system, defines and evaluates the tourism resources of Qingyang Red Cultural Heritage scientifically and objectively, and puts forward that the red cultural heritage resources in Qingyang Old District should be integrated in the mode of "red stage building, green singing".
\end{abstract}

\section{Introduction}

Qingyang red cultural heritage resources are widely distributed, but relatively concentrated at the same time, its distinctive characteristics, not only covers the land war of all kinds of red cultural heritage, but also has its own characteristics compared with the red cultural heritage resources in other regions. It is beneficial to promote the development of Qingyang tourism industry by studying the types and characteristics of Qingyang red tourism resources, value evaluation and integration, and development strategies.

\section{Overview of Red Cultural Heritage Resources in Qingyang Old District}

\subsection{The Historical Status of the Old Revolutionary Areas in Qingyang}

Qingyang revolutionary base area has experienced three main stages of development: the period of guerrilla revolution base area period, the period of Zhaojin revolutionary base area period, and the period of southern Liang revolutionary base area. Nanliang is located $50 \mathrm{~km}$ to the east of Huachi County, Qingyang City. It is the seat of the government of Shaanxi-Gan Soviet government and is called the Nanliang Government. The monastery tableland is located in Zhengning County, Gansu Province. At that time called Xinzheng County. Zhaojin is located in the northwest of Yaaozhou District, Shaanxi Province, with Zhaojin Town in Yaozhou District as the center, across Yaozhou District, Xunyi, Chunhua, Yijun and other counties. The three revolutionary bases gleamed in the annals of the new democratic revolution under the leadership of the Communist Party of China and made immortal contributions to the victory of the Chinese revolution. Have an important position and function.

\subsection{Types and Characteristics of Qingyang Red Cultural Heritage Resources}

(1) Types of Qingyang Red Cultural Heritage Resources Qingyang's revolutionary relics, revolutionary memorial venues and so on are numerous and rich in types. Among them, there are ruins, ruins and old houses, sites and so on that occurred during the period of the Shaanxi-Ganbian Revolutionary Base area. There are also memorial halls and mausoleums for revolutionary martyrs, which are important red cultural tourism resources. (2) Characteristics of Qingyang Red Cultural Heritage Resources. 1) numerous in quantity and rich in types. Qingyang red cultural tourism resources are rich in type and numerous in quantity. The heritage resources are among the 100 classic scenic spots of red cultural heritage tourism in the whole country and the national defense education base one in the whole province. There are 1 national 3A level tourist attractions, 4 city red cultural tourist attractions and 3 Communist Party history education bases. Revolutionary traditional education base and clean government education base 2. The city's 33 red cultural 
heritage resources were named cultural relics conservation units above the county level, of which 8 provincial cultural protection units. The city and county level cultural protection unit 13 . The whole city has the name above the county level patriotism education base to have or the patriotism education demonstration base. This has provided the abundant for the Qingyang old area red cultural heritage development. 2) The resource base of strong resource concomitant. Most of the red cultural heritage resources in Qingyang Old District are accompanied by natural ecology and social and humanistic tourism resources. At the same time they feel the magnificent history of modern Chinese revolution. At the same time, we can appreciate the rich forest resources and wild animals and plants in Ziwuling, and can appreciate the spiritual connotation of Chinese farming civilization, which truly reflects the red culture, the beautiful ecology and the long history civilization. 3) The spirit and culture are distinct. Compared with natural tourism resources, Qingyang red cultural tourism resources to a large extent contains the content of spiritual culture. These spiritual and cultural contents can be reflected by certain material entities, such as red ballads and slogans. The spiritual and cultural characteristics of the red cultural tourism resources require us not only to pay attention to the tangible resource entities, but also to excavate its rich spiritual and cultural connotations when we develop the red cultural tourism resources. Mold red cultural taste.

\section{Present Situation of Utilization of Qingyang Red Cultural Tourism Resources}

The present situation analysis of Qingyang red cultural tourism mainly presents the following characteristics: (1) tourists mainly come from the peripheral areas of Northwest China, and the tourist market is narrow; (2) Compared with many traditional tourism resources in the revolutionary base area of Shensi-Kansu-Ningxia Border region, Qingyang's red cultural tourism resources were developed later, and many red scenic spots were not well combined with local natural resources, local customs and customs. (3) Qingyang is located in the hinterland of the Loess Plateau, the loess ecological environment is relatively fragile and the exploitation is difficult, thus weakening its economic utilization value; (4) Red cultural heritage tourism resources are basically in their own blind state of development, rarely with other regions of the red cultural heritage resources joint development. (5) Lack of unified destination image and slogan. The propaganda is weak, the theme is not clear-cut, and the historical popularity is not well transformed into the tourism image popularity. Most red scenic spots stay in the state of the reception economy of the government groups. (6) Most of the development projects are lack of special features, which are limited to the stage of tourism product development, and finally lead to the simplification and homogeneity of tourism products. (7) Most of the red cultural heritage tourism projects lack shock and experience, and can not meet the needs of tourists. There is no interaction and resonance with tourists. All these make the marketing consciousness and strategy of red cultural tourist attractions need to be strengthened. Therefore, Qingyang's red cultural tourism resources need to be systematically integrated, developed and utilized.

\section{Evaluation of Red Cultural Tourism Resources in Qingyang}

\subsection{Evaluation Principles and Methods}

(1) Evaluation principles. According to the type, distribution and characteristics of the red cultural heritage resources of Qingyang, we should adhere to the principles of objective practical principle, comprehensive system principle and dynamic development principle. (2) Analytic Hierarchy Process (AHP). The analytic hierarchy process is generally divided into six basic steps. Explicit goal; build a hierarchical model; construct a decision matrix. Hierarchical order ordering; hierarchical ordering; check consistency. In the AHP analysis method, the most important task is to calculate the maximum feature root and the corresponding feature vector of the judgment matrix. The calculation steps of this method are as follows.

Calculate the product of each row element of the judgment matrix $M_{i}=\prod_{j=1}^{n} b_{j}(i=1,2, \ldots n)$, 
Calculate the root $\bar{w}_{i}=\sqrt[n]{M_{i}}(i=1,2, \ldots n)$,

Calculate normalized vector $\bar{w}=\left[\bar{w}_{1}, \bar{w}_{2}, \ldots \bar{w}_{n}\right]^{T}$,

Calculate eigenvector $w_{i}=\bar{w}_{i} / \sum_{i=1}^{n} \bar{w}_{i}(i=1,2, \ldots n)$,

Calculate greatest characteristic root $\lambda_{\max }=\sum_{i=1}^{n} \frac{(A w) i}{n w_{i}}$.

\subsection{Construction of Qingyang Red Culture Tourism Resources Evaluation System}

(1) Calculate Weight. The weight refers to the importance of the evaluation index in the evaluation system or the proportion of the evaluation index in the total score, whose quantitative expression is the weight. Table 1 lists the scale and its meaning. (2) Judgment matrix. The step is a key step of AHP judgment matrix for an element.

Table 1. Analytical Hierarchy Process Evaluation Scale and its meaning.

\begin{tabular}{ll}
\hline scale & criterion rule \\
\hline 1 & The same importance \\
\hline 3 & Moderate importance \\
\hline 5 & More importance \\
\hline 7 & very importance \\
\hline $2,4,6,8$ & absolute importance
\end{tabular}

According to the above two indicators of the following judgment matrix and its weights of Qingyang red tourism resources. The judgment matrix and its weights data Table 2, Table 3, Table 4, Table 5.

Table 2. The B layer on the target a layer judgment matrix and its weights.

\begin{tabular}{|c|c|c|c|c|}
\hline A & $\mathrm{B}_{1}$ & $\mathrm{~B}_{2}$ & $\mathrm{~W}_{\mathrm{i}}$ & Sorting \\
\hline $\mathrm{B}_{1}$ & 1 & 6 & 0.857 & 1 \\
\hline $\mathrm{B}_{2}$ & $1 / 6$ & 1 & 0.143 & 2 \\
\hline
\end{tabular}

NOTE: $\lambda \max =2, C I=0, R I=0, C R=0<0.10$

Table 3 . The $\mathrm{C}$ layer to the $\mathrm{B}_{1}$ layer judgment matrix and weight.

\begin{tabular}{lllllll}
\hline $\mathrm{B}_{1}$ & $\mathrm{C}_{1}$ & $\mathrm{C}_{2}$ & $\mathrm{C}_{3}$ & $\mathrm{C}_{4}$ & $\mathrm{C}_{5}$ & $\mathrm{~W}_{\mathrm{i}}$ \\
\hline $\mathrm{C}_{1}$ & 1 & 5 & 5 & 4 & 2 & 0.466 \\
\hline $\mathrm{C}_{2}$ & $1 / 5$ & 1 & 1 & $1 / 2$ & $1 / 2$ & 0.089 \\
\hline $\mathrm{C}_{3}$ & $1 / 5$ & 1 & 1 & 2 & $1 / 2$ & 0.117 \\
\hline $\mathrm{C}_{4}$ & $1 / 4$ & 2 & $1 / 2$ & 1 & $1 / 3$ & 0.098 \\
\hline $\mathrm{C}_{5}$ & $1 / 2$ & 2 & 2 & 3 & 1 & 0.231 \\
\hline
\end{tabular}

NOTE: $\lambda \operatorname{\lambda max}=5.404, C I=0.098, R I=1.12, C R=0.089<0.10$

Table 4. The $C$ layer to the $B_{2}$ layer judgment matrix and weight.

\begin{tabular}{lllll}
\hline $\mathrm{B}_{2}$ & $\mathrm{C}_{1}$ & $\mathrm{C}_{2}$ & $\mathrm{C}_{3}$ & $W_{i}$ \\
\hline $\mathrm{C}_{1}$ & 1 & $1 / 2$ & $1 / 4$ & 0.143 \\
\hline $\mathrm{C}_{2}$ & 2 & 1 & $1 / 2$ & 0.286 \\
\hline $\mathrm{C}_{3}$ & 4 & 2 & 1 & 0.572 \\
\hline
\end{tabular}

NOTE: $\lambda \max =3, C I=0, R I=0.52, C R=0<0.10$ 
Table 5. B-C layer judgment matrix and its weights.

\begin{tabular}{lllll}
\hline $\mathrm{B}-\mathrm{C}$ & $\mathrm{B}_{1}$ & $\mathrm{~B}_{2}$ & $\mathrm{~W}_{\mathrm{i}}$ & Sorting \\
\hline & 0.857 & 0.143 & & \\
\hline $\mathrm{C}_{1}$ & 0.466 & & 0.399 & 6 \\
\hline $\mathrm{C}_{2}$ & 0.089 & & 0.076 & 3 \\
\hline $\mathrm{C}_{3}$ & 0.117 & & 0.100 & 4 \\
\hline $\mathrm{C}_{4}$ & 0.098 & & 0.084 & 2 \\
\hline $\mathrm{C}_{5}$ & 0.231 & & 0.198 & 8 \\
\hline $\mathrm{C}_{6}$ & & 0.143 & 0.020 & 7 \\
\hline $\mathrm{C}_{7}$ & & 0.286 & 0.041 & 5 \\
\hline $\mathrm{C}_{8}$ & 0.572 & 0.085 & \\
\hline
\end{tabular}

NOTE: $\lambda \max =4.020, C I=0.01, R I=1.41, C R=0.007<0.10$

Consistency check. According to the judgment matrix of the above structure, calculate the maximum characteristic root $\lambda_{\max }$ and the feature vector of each judgment matrix $w$ by using the square root method, $\mathrm{CI}$ is the index of the consistency of judgment matrix. $C_{I}=\frac{\lambda_{\max }-n}{n-1}$. And, find the corresponding average random consistency indicator RI, as shown in the Table 6.

Table 6. Corresponding average random consistency indicator RI.

\begin{tabular}{clllllllll}
\hline order & 1 & 2 & 3 & 4 & 5 & 6 & 7 & 8 & 9 \\
\hline RI & 0 & 0 & 0.52 & 0.89 & 1.12 & 1.26 & 1.36 & 1.41 & 1.46
\end{tabular}

$\mathrm{CR}$ is the proportion of random consistency of judgment matrices. If $C R=\frac{C I}{R I}<0.10$, It is considered that the judgment matrix has satisfactory consistency; otherwise, the judgment matrix of this level will be adjusted until the consistency test of the total ranking of the hierarchy meets the requirements.

\subsection{Consistency Test Result}

It can be seen that the above calculation results have reached the requirement of consistency.

\subsection{Analysis of Results}

(1) Total goal. From the overall goal, the red cultural heritage of Qingyang tourism resources evaluation system, its characteristic is the main driving force of Qingyang red cultural heritage tourism resources evaluation, the weight is 0.857 . But the Qingyang red cultural heritage tourism resources are affected by some other factors which influence, its weight is 0.143 , should try to overcome these factors the affected. (2) Index level. The red cultural heritage of Qingyang tourism resources evaluation system, in addition to its own characteristics in terms of resources, the development of red cultural heritage is to make great efforts, the depth of excavation of red cultural heritage tourism resources new, maintenance of existing resources, its weight is 0.198; the most famous, its weight is 0.399 increase; on the development of strength, its weight is 0.076 ; the ornamental also needs further cultivation, its weight is 0.084 ; while the weight of science education is 0.100 , but it is the patriotic education and national defense education value. In the restricting factors, the key factors in the development of Qingyang natural tourism resources evaluation is not affected, its weight is only 0.020 ; the seasonal weight is 0.041 , the resource development is not ideal; the cost of inputs its weight is 0.082, which is Qingyang red cultural heritage tourism resources evaluation Major factors, the government should increase investment and infrastructure construction. The weight of red cultural heritage resources for science popularization education 0.198, weight is 0.100 , the proportion of relatively large, the two as the focus of Qingyang red cultural heritage resources development, in the development process to highlight its characteristics, to focus on the development. 


\section{Analysis of the integrated development and comprehensive utilization of red cultural heritage resources in Qingyang}

\subsection{Integrated Development and Utilization Pattern of Red Cultural Heritage Resources in Qingyang}

Qingyang would enhance the connotation of tourism products, mine the red cultural heritage resources, focuses on market demand, make good red cultural heritage tourism products, flexible use of "red green stage, singing and other marketing strategies, realize the sustainable development of Qingyang old liberated areas in red cultural tourism.

\subsection{Integrated Development and Comprehensive Utilization of Red Cultural Heritage Resources in Qingyang}

(1) Deeply excavate the characteristics of red cultural heritage resources and form the pattern of regional product diversification. Qingyang has to diversify its development path of red cultural heritage, create a boutique of red cultural heritage tourism routes, meet different tourism needs, so as to enhance its market competitiveness and make the red cultural heritage tourism go deep development and wide development. (2) Improve the participation of red cultural tourism projects. Design and development of Qingyang red culture tourism project in the premise of insisting on the development and education, pay attention to participate in the consideration of the launch, tourists hands-on experience tourism project design. The red cultural heritage tourism and natural green ecological tourism combining the Loess and unique natural landscape rich cultural landscape and social combination true, the formation of organic integration of the region's various tourist attractions, tourist routes and the appropriate docking, pattern of positive cooperation and development in different tourism areas.

\subsection{Perfect the Red Cultural Heritage Tourism Facilities}

The government should create a good investment environment, attract a wide range of financial support and participation from all sectors of society, the common development of red cultural heritage tourism service facilities related to the junction of Shaanxi and Gansu and other related tourism projects, to create for the development of Qingyang old red cultural heritage tourism and the wider platform.

\subsection{Speed up the Construction of Infrastructure and form a Convenient Large Tourist Channel}

The bottleneck of Qingyang red culture tourism development is not smooth. Tourism channel development strategy of red tourism in Qingyang to fully integrate the red tourism area of Shaanxi Gansu Ningxia must set up the construction of tourism channel. Must strive for Qingyang to Beijing, the Yangtze River Delta, and Pearl River Delta route to get all open. Speed up the construction of Yinchuan-Xi 'an high-speed rail Qingyang section, Qingyang City will be built to connect Yinchuan City to Xi'an City tourism channel transfer station, so that Qingyang really integrated into the Shaanxi-Gansu-Ningsia red tourist area, in Xi'an. Yinchuan tourism hot spots led by rapid development, led rapid development by Xi'an, Yinchuan tourism hot spots.

\section{Acknowledgements}

The paper is the annual strategic research project of colleges and universities in Gansu: the periodical result of the way to improve the overall competitiveness tourism industry under the "One Belt and One Road “strategy in Qingyang (Project No. 2017F - 27).

\section{References}

[1] Liu Hai, Ming Jing. Red Tourism: conceptual Development process and Development Model [J]. Journal of Hunan University of Business (bimonthly): 66-71. 
[2] Xiao Hai, Lu liang. Trademark Protection Strategy of Red Tourism Resources [J]. Intellectual property 2009, 1: 40.

[3] Li Rong. On the status and the role of Shaanxi-Ganbian Revolutionary Base area [J]. A study of the history of the Communist Party of China: 11: 12-18.

[4] Tang Li. A study on the Evaluation and Development of Red Tourism Resources in Xingan County, Guangxi [D]. Guangxi: Guilin Institute of Technology, 2006-05-01: 17.

[5] Qingyang Municipal Committee of the Communist Party of China. Revolutionary ruins. [EB/OL]. http://www.qysw.gov.cn/hsqy/gmyz/.

[6] Wang Fei. Strategic thinking on the Development of Qingyang Red Cultural Heritage [J]. Productivity studies.

[7] Baidu encyclopedia. Qingyang. [EB/OL]. http://baike.baidu.com/view/734344.htm\#7.

[8] Xu J P, Hu Z N, Li Jun. Operations Research [M]. Beijing: science Publishing House. 2004. 